\title{
Hacia una pedagogía de la sexualidad socialmente relevante. Mapeos sobre discriminación y orientaciones pedagógicas para educar en la diversidad de género
}

Towards a pedagogy of socially relevant sexuality. Mapping on discrimination and pedagogical orientations to educate on gender diversity

\author{
Santiago Zemaitis \\ Facultad de Humanidades y Ciencias de la Educación- \\ Universidad Nacional de La Plata/ CONICET-Instituto de \\ Investigaciones en Humanidades y Ciencias Sociales (IdIHCS), Argentina \\ zemaitis.santiago@gmail.com
}

Constanza Pedersoli

Facultad de Humanidades y Ciencias de la Educación-

Universidad Nacional de La Plata, Argentina

copedersoli@fahce.unlp.edu.ar

\section{Resumen:}

Alumnxs con madres y/o padres del mismo sexo, docentes que luchan por ser respetadxs con independencia de sus elecciones sexogenéricas, o niñxs que deciden cambiar su identidad, son ejemplos concretos de los modos en que las escuelas comienzan a abrirse a la experiencia de las diversidades corporales, sexuales e identitarias. Sin embargo, aunque existen programas de educación sexual y hubo avances significativos en materia de protección de estas experiencias, las violencias contra jóvenes LGBTI siguen persistiendo. En este artículo nos interesa plantear dicha tensión a partir de un mapeo de estudios y relevamientos estadísticos que vienen dando cuenta de la continuidad de las violencias, los hostigamientos y agresiones que sufren aquellxs estudiantes jóvenes que no siguen las normas hegemónicas de los géneros. Por otra parte, proponemos una reflexión sobre la necesidad de algunos recaudos conceptuales en los modos de nombrar estas violencias con el fin de reposicionarlas como "violencia por prejuicio contra las orientaciones sexuales y las identidades de género no normativas", en el marco de las violencias de género. También comprendiéndolas como fenómenos sociales y no como "casos" individuales. Finalmente proponemos algunas líneas orientativas sobre lo que consideramos un tipo de educación sexual socialmente relevante (Britzman, 2002).

Palabras claVe: Diversidad sexual, Educación sexual integral, LGBTI, Violencia de género.

\section{Abstract:}

Students with parents (mother and/or father) with the same-sexpartner; teachers who fight for equality of gender minorities, and childrens who decide to change their gender identity, are examples of the way in which schools become opens to the body, sexual, and identity experience. In this regard, in a first section, though one can recognize formal improvements in government programs of sex education, violence against LGBTI (Lesbian, Gay, Bisexual, Transgender and Intersexual) young still persists. In this paper we discuss this aparent contradiction on the light of quatitative data which show current and sistematic violence against young students who do not identify them self with hegemonic gender/sexual identities. In a second section, we present some conceptual recalls in the ways of naming these violence for the purpose of repositioning them as "violence for prejudice against sexual orientations and non-normative gender identities", within the framework of gender violence, understanding them as social phenomena and not as individual "cases". In the third and last section, we propose some guidelines on what we consider to be a socially relevant sex education type (Britzman, 2002).

KEYWORDS: Sexual diversity, Integral sexuality, Education, LGBTI, Gender violence . 


\section{INTRODUCCIÓN ${ }^{1}$}

A inicios del siglo XXI asistimos a un claro reconocimiento y avance en propuestas de educación sexual y derechos sexuales y reproductivos como parte de una asignatura obligatoria en diferentes países. Las políticas de educación sexual en Latinoamérica vienen ganando terreno no solo en el ámbito legislativo, sino también en el sistema educativo a partir de la producción de documentos de orientación conceptual y pedagógica sobre la educación sexual.

Sin embargo, al mismo tiempo, existen evidencias de altos niveles de discriminación, violencia y hostigamiento hacia personas LGBTI, ${ }^{2}$ tal como se desprende de los resultados de encuestas e informes realizados en distintos países. Sobre esta tensión, entre otras cuestiones, nos preguntamos: ¿qué tipo de educación se hace necesaria ante la persistencia de este tipo de violencias? y ¿qué tipo de propuestas pedagógicas pueden pensarse en este marco?

Analizando la situación contemporánea en cuanto a los avances legales y curriculares en torno a la educación sexual, De Maria, Galárraga, Campero y Walker (2009) han mostrado, a través de una encuesta en 27 países de la región latinoamericana, que Argentina, Brasil y Costa Rica son quienes tienen una legislación más avanzada en contenidos curriculares obligatorios relacionados con la educación sexual y prevención del HIV; mientras que la mayoría de los países (Bolivia, Chile, Colombia, Ecuador, El Salvador, Honduras, Nicaragua, Perú, República Dominicana, Uruguay y Venezuela) sólo alcanzan un nivel medio de implementación en materia legislativa. A su vez, Haití, México y Panamá han mostrado un desarrollo bajo en estos parámetros y, en Antigua y Barbuda, Bahamas, Barbados, Guyana, Jamaica, Paraguay, Santa Lucía, Suriname, y Trinidad y Tobago no existe legislación alguna ni avances de políticas en materia de educación sexual.

En algunos países donde la educación sexual escolar se implementa, se presenta más como una propuesta curricular transversal que como una asignatura específica. También interesa señalar que, en las escuelas secundarias, la educación sobre la sexualidad cubre un amplio rango de temas relevantes aunque quedan otros pendientes como la discriminación por orientación sexual o identidad de género.

Siguiendo a Jesica Baez y Catalina González del Cerro (2015), la tendencia generalizada a favor de la inclusión de la noción de "sexualidad integral" y de la perspectiva de derechos sexuales y reproductivos es notoria, así como la incorporación del enfoque de género en las normativas de varios países. Sin embargo, advierten las autoras: "existe una gran heterogeneidad de interpretaciones y procesos de implementación que se desarrollaron en cada país según las particularidades de sus naciones y sus gobiernos” (p. 8).

En la Argentina, contamos desde el año 2006 con la Ley de Educación Sexual Integral (ESI) y, a partir del año 2008, con el Programa Nacional de ESI perteneciente al Ministerio de Educación Nacional. Ambos avances han vuelto obligatoria la enseñanza de la educación sexual desde el nivel inicial hasta la formación superior, tanto en instituciones de gestión estatal como privada. Los Lineamientos Curriculares de la ESI (2008), sustentados desde una perspectiva de la integralidad y desde los enfoques de género y de derechos humanos trascienden la clásicas miradas heterosexistas de los géneros y biologicistas de la educación sexual, que se centran en la prevención de embarazos y enfermedades. Entre los contenidos y orientaciones de la ESI se incluyen: el respeto por la diversidad sexual, el derecho a la no discriminación a niñxs y adultxs que viven y experimentan corporalidades y sexualidades de formas no heteronormativas, como así también, la incorporación de distintos modos de organización familiar. ${ }^{3}$ Siguiendo una encuesta realizada por la coordinación del Programa ESI sobre el desarrollo de la formación y capacitación docente del Programa Nacional de ESI, puede decirse que hasta mediados del año 2015 habían sido capacitadas todas las escuelas de las provincias de Formosa, Salta, Chubut, La Pampa, Río Negro, Jujuy, La Rioja, Tierra del Fuego, Santa Cruz, Neuquén, Misiones y Chaco. Durante el desarrollo de aquella encuesta, las provincias de Buenos Aires, Mendoza, Córdoba, Entre Ríos, San Luis, Corrientes y Catamarca se encontraban aún en proceso 
de capacitación. Hacia fines del año 2014 se capacitaron 28.500 escuelas y 71.000 docentes (Ministerio de Educación de la Nación, 2015). ${ }^{4}$

Teniendo en cuenta este contexto, en la primera sección de este artículo reseñamos un conjunto de estudios y relevamientos estadísticos que vienen dando cuenta de la persistencia de violencias, hostigamientos y agresiones sistemáticas a estudiantes jóvenes que no siguen las normas hegemónicas de los géneros, o bien, se identifican con otros modos de placer y formas de desplegar su autoadscripción identitaria. En la segunda sección, presentamos algunos recaudos conceptuales en los modos de nombrar estas violencias, a los fines de reposicionarlas como "violencia por prejuicio contra las orientaciones sexuales y las identidades de género no normativas"; situándolas en el marco de las violencias de género y entendiéndolas como fenómenos sociales y no como "casos" individuales. Por último, mencionamos algunas propuestas que podrían ser desplegadas en lo que algunxs autorxs han denominado "una educación sexual socialmente relevante".

\section{BREVE MAPEO DE ESTUDIOS SOBRE VIOLENCIAS POR PREJUICIOS DE GÉNERO}

En la finalización del siglo XX y los inicios del XXI se hicieron notorios algunos avances sobre la despatologización y la descriminalización de la homosexualidad y sobre la ampliación de derechos civiles de personas del mismo sexo. Un hecho a destacar sucedió en 1990, cuando la Organización Mundial de la Salud (OMS) retiró la homosexualidad de su lista de enfermedades mentales. En la década del noventa más de 40 países habían prohibido los crímenes de odio homofóbicos y, más recientemente, en 2017 eran ya 24 los que habían reconocido el matrimonio civil entre personas del mismo sexo.

Sin embargo, en la actualidad, son 72 los países que aún siguen penalizando las relaciones entre personas del mismo sexo: en más de la mitad de los países del mundo las personas LGBTI pueden encontrarse desprotegidas ante la discriminación en el ámbito laboral (Stonewall, 2018); la mayoría de los gobiernos niega al colectivo trans (travestis, transexuales y transgéneros) el derecho a cambiar legalmente su nombre y su género (Ibid.); y, en el lado más extremo de la violencia, la pena de muerte a personas homosexuales está actualmente 'permitida', o bien existe evidencia de su existencia, en por lo menos 8 países. Claramente no estamos frente a un balance celebratorio.

A fines del año 2014, la Comisión Interamericana de Derechos Humanos (CIDH) publicó los resultados de un monitoreo sobre las violencias a personas LGBTI en Latinoamérica a través de información y datos ofrecidos por los 25 países miembros de la OEA -entre ellos la Argentina- realizado entre el $1^{\circ}$ de enero de 2013 y 31 de marzo de 2014. ${ }^{5}$ En ese plazo, del total de 770 actos de violencia contra personas LGBT registrados, 594 personas resultaron asesinadas y 176 fueron víctimas de graves ataques. El informe concluye que: "El denominador común de esta violencia es la idea que tiene el perpetrador de que la víctima ha trasgredido las normas de género aceptadas" (CIDH, 2014, p. 1).

En las últimas dos décadas se conocieron también relevamientos estadísticos e investigaciones referidos a la percepción de los estudiantes LGBTI sobre los maltratos recibidos y sobre la inclusión (o no) del abordaje de la temática de la diversidad sexual dentro del currículum escolar. Esto ha sido constatado en publicaciones y/o informes de investigación, tanto de organismos gubernamentales como de organizaciones sociales. Detengámonos en algunos de estos resultados.

El Movimiento de Integración y Liberación Homosexual en Chile (MOVILH), el movimiento homosexual más antiguo de ese país, publicó en 2012 la "Encuesta sobre Educación Sexual y Discriminación", que fue aplicada a 10 Liceos de zonas metropolitanas y contó con respuestas de más de 250 estudiantes. Los resultados arrojaron que el $21 \%$ de los estudiantes "ha escuchado 'siempre o a veces' comentarios discriminatorios de parte de sus docentes, cifra que se eleva al 61.2 por ciento cuando se hace sólo referencia a prácticas o reglamentos contrarios a las relaciones sociales entre personas del mismo sexo" (p. 11). Asimismo, el 39 \% conocía casos concretos de discriminación hacia la diversidad sexual, mientras que, "sólo el $33.2 \%$ 
reportó que 'siempre (12\%) o a veces (21.2\%)' se sanciona a lxs responsables de los atropellos” (p. 11). Desde esta encuesta se concluye que existe:

(...) una demanda amplia en los establecimientos para abordar la sexualidad en clases, que es mayor a la institucionalizada, mientras que las mismas requieren incluir temáticas sobre la orientación sexual y la identidad de género, pues son escasas en las aulas, de acuerdo a la percepción de lxs estudiantes (p. 11).

En Ecuador, la investigación realizada por Pinos-Vélez y Pinos (2011) mostró, entre otros resultados, que de 1.130 estudiantes, 252 (22,3\%) presentaron un alto nivel de creencias prejuiciadas hacia personas LGBT. Según este estudio:

(...) el mito que resultó más arraigado es el que manifiesta que se puede elegir la orientación sexual 864 (76,5\%); luego, $401(35,5 \%)$ consideraron que la homosexualidad puede ser curada con terapia; $393(34,8 \%)$ consideraron que la homosexualidad es un pecado; para $315(27,9 \%)$ la homosexualidad es una enfermedad (p. 8).

La primera Encuesta Nacional sobre Bullying Homofóbico realizada en México en 2012 fue aplicada a 1.273 personas LGBTTTIQ, de las cuales el 67\% afirmó que fue víctima de bullying. El 28\% y el 56\% identificaron respectivamente a las escuelas primarias y secundarias como los ámbitos donde se reportaron más maltratos por su orientación. En relación a "la reacción de los profesores y autoridades escolares", el 24\% afirmó que "no se percataba del bullying" y el 48\% respondió que "nada, les parecía algo normal”. Solo un 14\% señaló que "llamaba la atención a los agresores" (Homozapping, 2017). En relación con las consecuencias sobre las trayectorias educativas, el $76 \%$ reconoció que uno de los efectos del acoso es el "bajo rendimiento escolar”, el 61\% manifestó “no querer ir a la escuela”, el $71 \%$ admitió “pérdidas de amistades”, y el 49\% aseguró haber sufrido "depresión".

Datos similares surgen de estadísticas realizadas en otros países, como por ejemplo, la primera Encuesta de Clima Escolar LGBT de Colombia en 2016, ${ }^{6}$ las primeras investigaciones oficiales de Brasil en 2011, ${ }^{7}$ así como también, los Informes Anuales de Perú elaborados desde 2008, ${ }^{8}$ sobre Derechos Humanos de personas Trans, Lesbianas, Gays y Bisexuales. En Venezuela se destacan, desde 2003, los informes sistemáticos de Acción Ciudadana Contra el Sida (ACCSI) y, a partir del 2012, los correspondientes a la ONG DIVERLEX.'

En términos más globales, un informe de la UNESCO publicado en 2013, que recoge datos de todos los continentes, advierte que aun cuando son pocos los países que han recopilado información estadística en relación con estas situaciones, los datos disponibles permiten asegurar que "la magnitud del problema es importante" (UNESCO, 2013, p. 20). En el mismo informe se advierte que dichos datos han mostrado cómo las situaciones de violencia por prejuicio de género tienen impacto en los aprendizajes, la disminución de asistencia a la escuela, la deserción escolar temprana y los logros y rendimientos académicos. Para el caso de nuestro país, el informe de la UNESCO señala que:

(...) lxs estudiantes transgénero informaron haber detenido sus estudios debido al bullying efectuado por otrxs estudiantes o porque las autoridades escolares les negaron el ingreso. De lxs estudiantes encuestadxs, un 45\% abandonó la educación secundaria y sólo un 2,3\% logró completar la universidad (p. 23).

También en la Argentina se dispone de datos sistemáticos propios en torno a las violencias hacia estudiantes LGBTI. En el año 2016, diez años después de la histórica sanción de la Ley de Educación Sexual Integral, se dieron a conocer los resultados de la Primera Encuesta Nacional de clima escolar para jóvenes LGTB ${ }^{10}$ liderada por la Asociación Civil 100\% Diversidad y Derechos que impulsa el desarrollo de políticas públicas referidas a la diversidad sexual y de género. La muestra estuvo compuesta por un total de 781 estudiantes entre las edades de 13 y 18, procedentes de las 23 provincias y la Ciudad Autónoma de Buenos Aires. Los resultados mostraron que, a pesar de los avances de las legislaciones vigentes en materia de derechos humanos y de educación, existen todavía muchos obstáculos (institucionales, sociales y culturales) en el acceso de las personas LGBT a ciertos derechos elementales. La encuesta mostró que suelen sentirse insegurxs 
en el ámbito escolar y que escucharon y fueron objeto de comentarios peyorativos y homofóbicos como "puto", "maricón" o "torta". A su vez, aproximadamente la mitad de lxs jóvenes encuestadxs declaró que, a pesar de haber recurrido a personal de la escuela para denunciar las situaciones de acoso, esto no se tradujo en intervenciones que resultaran efectivas. Aunque en menor medida, los encuestados también manifestaron haber sido objeto de violencia física; $y$, casi la mitad de lxs jóvenes encuestadxs declaró que, a pesar de haber recurrido a personal de la escuela para denunciar las situaciones de acoso, esto no se tradujo en intervenciones que fueran efectivas.

El relevamiento de esta encuesta mostró además que ese clima escolar hostil tenía un alto impacto en los índices de ausentismo y en el rendimiento académico de lxs jóvenes: el 67,9\%, alrededor de dos tercios, reportaron haberse sentido inseguros en la escuela durante el último año por situaciones de discriminación vinculadas a su orientación sexual y el 36, 3\% manifestó no haber asistido al menos una vez a clase durante el último mes. Esto impacta directamente sobre las trayectorias escolares por ejemplo, el 14,2\% aseguró haber cambiado de escuela el último año, de los cuales el 3,8\% lo hizo más de una vez. A su vez, hace variar la frecuencia en la asistencia y el tiempo vivido dentro de la escuela, como así también, tienden a evitar la presencia en ciertos lugares. Así, el 43,8\% afirmó que evita clases de gimnasia, el 27,3\% los espacios de recreación y, en un mayor porcentaje, el 36,3\% señaló que prefiere no circular por los baños de la escuela.

Estos informes permiten observar que la violencia por prejuicios de género afecta las trayectorias educativas de lxs estudiantes que la padecen y genera circuitos espaciales diferenciados dentro de las escuelas. Los avances y leyes progresistas son un hecho, como lo han indicado otros antecedentes, sin embargo, "seguimos asistiendo a impactantes crímenes de odio contra personas homosexuales y trans en virtud de su pertenencia a dicha categoría social en muchos países" (Barrientos, 2016, p. 350).

Si actualmente disponemos de estos y otros datos es, en buena medida, gracias a las organizaciones LGBT, como también, en algunos casos, a las acciones directas del Estado tal como sucede en Brasil o en la Argentina. Esto indica la importancia del trabajo conjunto entre asociaciones civiles, dependencias estatales y escuelas en el desarrollo de investigaciones y monitoreos, como así también, en el diseño e implementación de acciones institucionales que tengan entre sus objetivos la erradicación de estas violencias desde una perspectiva de diversidad de género. Ahora bien, el mapeo anterior advierte sobre el estado de situación actual de los colectivos LGBTI y nos coloca ante una diversidad de formas de nombrar dichas violencias, cuestión a la que haremos referencia en el siguiente apartado.

\section{NOMBRAR LAS VIOLENCIAS PARA COMPLEJIZAR LA MIRADA}

Como señalamos anteriormente, acordamos con la definición propuesta en el informe publicado por la CIDH en 2015 donde las agresiones contra las personas LGBTI, lejos de ser consideradas como un acto individual, son entendidas como manifestaciones de violencia social que reflejan un fenómeno complejo y multifacético En dicho informe, la CIDH llama "violencia por prejuicio contra las orientaciones sexuales y las identidades de género no normativas" a este tipo de actos. Se trata de una violencia, que se dirige contra grupos sociales específicos, que "tiene un impacto simbólico, y envía un mensaje de terror generalizado a la comunidad LGBT" (CIDH, 2015, p. 11).

A pesar de la popularidad que ha cobrado en las últimas décadas, nos alejamos conceptualmente de los usos del término bullying. La mayor parte de las encuestas y estadísticas consultadas, oficiales o no, apelan a bullying ${ }^{11}$ homofóbico para referirse al tipo de situaciones, conductas y sentimientos experimentados por los jóvenes LGBTI y para definir a este tipo de violencias. Bulling significa "matón", aludiendo a una relación "víctima-agresor" (Platero Méndez, 2008). Sin embargo, esta dicotomía invisibiliza la dinámica profunda de los climas escolares. En este sentido, identificamos cierta limitación en el uso de este concepto para el estudio de una problemática que, como se señaló antes, es un fenómeno social complejo y estructural, que no puede ser comprendido en términos individuales ni individualizantes. Coincidimos con el investigador australiano 
Daniel Marshall (2010), que pone en cuestión el uso de esta categoría en los discursos sobre la seguridad y el acoso (bullying):

El acoso es un problema cuando existe junto con el discurso de la seguridad (...) ya que es la principal forma en que los jóvenes queer están en la mira como sujetos que requieren la atención de autoridades y maestras/os, porque naturaliza al niño queer como una víctima ejemplar de la intimidación (p. 5).

Otra nominación recurrente de la que nos distanciamos, puesto que considera a las violencias como casos aislados por fuera de la trama social, es la de "crimen/es de odio a la comunidad LGBTI". A propósito de las violencias contra las mujeres, Rita Segato (2017) sugirió que la utilización de la noción de "odio" no resulta del todo eficiente para dar cuenta de las violencias en la medida que se vuelve una explicación monocausal, reduccionista y simplificadora, ya que alude al fuero íntimo y emocional. Lo mismo puede pensarse cuando los feminicidios se rotulan como "crimines pasionales", individualizando los casos y presuponiendo que el origen de dichas violencias se reduce al ámbito doméstico y a la relación de pareja.

En esta misma línea, el colectivo trans ha puesto en duda recientemente la utilización del sufijo "fobia" (trans-fobia, homo-fobia, etc.), que también suele utilizarse como modo de justificación de las violencias a estos colectivos. Tal como explica la activista trans Violeta Alegre, la fobia hace diluir las responsabilidades en tanto el término refiere a "un miedo intenso y desproporcionado ante objetos o situaciones concretas". Así, la fobia "convierte al victimario en víctima” (Alegre, 2017).

Una alternativa posible a las ya mencionadas es el uso de la denominación "violencia de género", si entendemos que esta categoría no es sinónimo directo de "violencia contra las mujeres" sino un tipo particular de violencia ya profusamente estudiado en las ciencias sociales contemporáneas (Femenías y Aponte Sánchez, 2008; Femenías y Soza Rossi, 2009; Lagarde, 2008; Laurenzo, Maqueda, Rubino, 2009; Segato, 2003, 2017; Femenías, 2013, 2015). En esta misma línea, Fidel (2014) señala que el término "género" es un concepto relacional que resulta de una construcción social vinculada a lo masculino y lo femenino en determinada cultura. En este sentido, la violencia de género afecta tanto a mujeres como a hombres, ya que "la violencia de género contra hombres es ejercida también mayoritariamente por hombres, y es producto de ese modelo de masculinidad autoritario y dominador hacia las mujeres y menores, que se siente cuestionado ante otros modelos de masculinidad u otras opciones sexuales" (Massolo, 2007 citada en Fidel, et. al, p. 14). Siguiendo estos recaudos conceptuales, podemos enmarcar lo que venimos denominando "violencia por prejuicio contra las orientaciones sexuales y las identidades de género no normativas" como formas de la violencia de género.

\section{HACIA UNA PEDAgOgía DE LA SEXUALIDAD SOCIALMENTE RELEVANTE}

Sostenemos que uno de los modos posibles de hacer frente a las violencias de género desde el campo y la acción educativos es el tratamiento pedagógico de la sexualidad y de las relaciones de género en el marco de propuestas de educación sexual. Aunque ésta es solo una de sus formas de abordaje, ya que se trata de un proyecto más amplio que debería ocupar permanentemente la atención de quienes tienen la responsabilidad pedagógica de la conducción de los procesos educativos dentro y fuera de las escuelas. En este último apartado, retomando los aportes de Deborah Britzman (2002), haremos referencia a algunas de las posibles líneas que podrían orientar proyectos educativos especialmente dirigidos a las generaciones jóvenes.

Britzman (2002) se opone a los modelos clásicos de la educación sexual (el biologicista, el sanitarista o el informativo) al esgrimir que fijan un conocimiento sobre ciertas identidades (hombre/mujer, hetero/ homosexual) limitando el modo en que los sujetos nos vinculamos con nosotrxs mismxs y con los otrxs. Esta pedagoga canadiense sugiere una educación sexual socialmente relevante, donde lxs niñxs y jóvenes no sean consideradxs como identidades a controlar, vigilar y normalizar, sino como reales "investigadorxs del sexo". La autora profundiza la idea y agrega que tampoco deben ser concebidos como identidades fijas, sino como 
subjetividades históricas e identificaciones que se modifican y mutan con el tiempo. Su apuesta pedagógica se orienta a la ampliación y cuestionamiento de la visión de los sujetos sobre el mundo de la sexualidad. Propone un currículum que rechace toda norma opresora de género y una pedagogía que propicie el desarrollo de la fantasía, la imaginación, la curiosidad y la libertad.

A partir de los aportes de esta autora ensayamos, a modo de cierre, algunas orientaciones posibles para el desarrollo de una educación sexual que aumente la visibilidad de las violencias por prejuicio de género.

En primer lugar, es importante reconocer que los intereses, las preguntas, las dudas o las inquietudes que lxs jóvenes se formulan son producto de las experiencias y situaciones vividas o atravesadas y representan momentos específicos de un proceso dinámico, abierto y en permanente movimiento: la construcción de la propia identidad. Interpretarlos como relatos de aspectos íntimos y privados de experiencias personales e individuales puede obstaculizar su tratamiento como vehículo y apertura hacia un vínculo pedagógico de confianza, desde el que se habilite el planteo de preguntas y dudas que suelen encontrarse en la base de tabúes, miedos, mitos y creencias e impactan directamente en la subjetividad y la sensibilidad. Aquello sobre lo que está permitido o prohibido hablar o preguntar, o bien, la habilitación o el ocultamiento de ciertas imágenes o discursos sobre el erotismo, no están regidos por pautas invariantes en términos culturales. Es posible vincular las distancias y las proximidades a temas sexuales dentro de cada cultura con los acercamientos y alejamientos entre generaciones, en este sentido, resulta urgente que lxs adultxs con alguna responsabilidad en los procesos de educación y socialización de las generaciones jóvenes revisemos nuestras propias perspectivas sobre la sexualidad y tomemos conciencia de nuestros propios prejuicios sobre lxs jóvenes, sus prácticas y consumos.

Aspirar a una pedagogía de la sexualidad con relevancia social implica, en un segundo lugar, el reconocimiento de los sujetos de la educación como sujetos sexuadxs. Posición que se aleja de aquella que percibe a la juventud (en particular a lxs jóvenes LGBT) como un grupo incontrolable, promiscuo o peligroso. Tal como advierten algunos estudios antropológicos de la juventud -en relación con las lógicas institucionales que pretenden normativizar las identidades genérico-sexuales disidentes y sus manifestaciones de deseo y expresión corporal-, la tarea institucional "debería alejarse de la ansiedad por clasificar, localizar o estabilizar el género y la orientación sexual de un chico o chica, en virtud de buscar en ese gesto imperioso una respuesta o explicación de su 'peculiaridad' y/o 'conflictividad'" (Elizalde, 2009, p.10). Este tipo de lógicas pueden reproducirse inclusive en aquellas propuestas de educación sexual integral que fomenten el respeto por la diversidad genérico-sexual.

Un tercer aspecto en estas orientaciones es la necesidad de reconsiderar las "culturas sexuales de los alumnos", siendo que lxs jóvenes portan aprendizajes y lecciones de sexualidad de manera irregular y asistemática a partir de las propias experiencias, por fuera de las relaciones con lxs adultxs. Lxs investigadorxs ingleses Debbie Epstein y Richard Johnson (2000) advierten sobre el riesgo y pérdida de sentido de una educación sexual que no tenga en cuenta los conocimientos y las identidades sexuales de lxs estudiantes, alejándose de los reales intereses de sus destinatarixs.

A su vez, resulta imperioso trabajar para que las escuelas se conviertan, cada vez más, en lugares amplios y respetuosos de las identidades que quieran asumir las diversas personas que forman parte de sus comunidades educativas: docentes, no docentes, alumnxs y familias. Es por ello que, un cuarto punto estaría dirigido a considerar la centralidad de la "perspectiva de género". Su enfoque teórico permite, justamente, comprender los cuerpos y las sexualidades como construcciones sociales, ayudando a mostrar que no existe solo un modo binario de vivir la corporalidad (femenino/masculino, mujer/varón, heterosexual necesariamente), sino que el deseo y la forma de estar en el mundo tienen muchas alternativas (Morgade, 2016). A su vez, este punto de vista permite una mirada crítica sobre las situaciones de discriminación o acoso, por ejemplo, al revisar los análisis basados en la perspectiva del bullying que cercenan, como hemos señalado anteriormente, las posibilidades de estudiar la complejidad multiforme de las violencias.

Atender, en quinto lugar, a los mecanismos por los cuales nos vamos constituyendo como sujetos sociales. Consideraremos que, los actuales procesos de socialización de las juventudes presentan un real desafío a todo 
acto de transmisión vinculado con el cuidado de la sexualidad y la exposición del propio cuerpo. Asistimos a un mundo de imágenes y mensajes que colaboran con la hipersexualidad y la sexualización compulsiva de casi todos los ámbitos y momentos de la vida social, donde se reproducen figuras estereotipadas sobre las identidades sexuales, muchas veces sexistas, heteronormativas y homofóbicas. Aquí incluimos discursos, estímulos y agencias socializadoras, tales como la publicidad, los medios masivos y las tecnologías de la información y la comunicación en la era digital. Se vuelve así evidente la incitación compulsiva a la sexualidad, que es utilizada desde el mercado de consumo en campañas publicitarias y ventas de innumerables productos o servicios; una suerte de obligación constante a "tener que" ser sexuado y deseable todo el tiempo como modo de existencia y valor social (Zemaitis, 2016).

Una pedagogía de la sexualidad socialmente relevante, lejos de eludir o evitar estas cuestiones, debería ser capaz de incorporarlas como parte de la formación ética y sexual y de fomentar su análisis crítico. Tal actitud crítica permitiría poner en duda las imágenes y los discursos hegemónicos, analizarlos detalladamente y reflexionar sobre los mensajes y sentidos que imprimen en la vida sexual y social y sobre el modo en que ello impacta en la sensibilidad y la manera de reconocernos como sujetos de deseo.

Finalmente, en relación con las disposiciones que deben tomar lxs docentes sobre el conocimiento de la sexualidad y sobre su enseñanza,la pedagoga argentina Beatriz Greco (2009) sostiene que será necesario un trabajo de cada docente consigo mismo, con sus modos de relacionarse con los saberes sobre la sexualidad, con las formas de mirar y reconocer a sus estudiantes y con sus posibilidades de hablar y escuchar. Plantea que es necesario habilitar el diálogo y evitar los silencios, señalando que es allí donde la experiencia cobra mayor valor. La experiencia aportada por lxs otrxs, desde esta línea, instala un vínculo de confianza en tanto implica "el diálogo, la narración, el relato, la historia singular escuchada y respetada, la palabra que circula sin 'apropiaciones cristalizadas'” (p. 58). En suma, será así que estaremos acercándonos a generar lugares de encuentro, proximidad, cercanía y confianza; marcos que resultan condiciones pedagógicas y humanas fundamentales para que cualquier acto de transmisión pedagógica sea posible.

\section{Bibliografía}

Alegre, V. (18 de enero de 2017). La transfobia no es una fobia: no es una enfermedad. En: Agencia Presentes, 18/01/2017. Recuperado de: http://agenciapresentes.org/2017/01/18/httpagenciapresentes-org20170118la-t ransfobia-no-una-fobia/

Baez, J. y González del Cerro, C. (2015). Políticas de Educación Sexual: tendencias y desafíos en el contexto latinoamericano. En Revista del IICE, (38), Buenos Aires.

Barrientos, J. (abril, 2016). Situación social y legal de gays, lesbianas y personas transgénero y la discriminación contra estas poblaciones en América Latina. Revista Sexualidad, Salud y Sociedad. En Revista Latinoamericana, 22, 331-354.

Boccardi, F. (2008). Educación sexual y perspectiva de género. Un análisis de los debates sobre la ley de educación sexual integral en Argentina. En Revista Perspectivas de la comunicación, 1 (12), 48-58, Universidad de la Frontera, Temuco, Chile.

Boccardi, F. (2010). La sexualidad en la red de discursos mediáticos. Una lectura de la construcción de la educación sexual en la prensa argentina. En Revista F@ro, Año 6, 12, Facultad de Ciencias Sociales, Universidad de Playa Ancha, Valparaíso, Chile.

Britzman, D. (2002). La pedagogía transgresora y sus extrañas técnicas. En Mérida Jiménez, R. (Ed.) Sexualidades transgresoras. Una antología de estudios queer. Barcelona: Icaría.

De Maria L.M; Galárraga, O.; Campero, L.; Walker, D.M. (2009). Educación sobre sexualidad y prevención del VIH: un diagnóstico para América Latina y el Caribe. En Revista Panam Salud Pública. 26 (6), 485-93. 
Elizalde, S. (2009). Normalizar ante todo. Ideologías prácticas sobre la identidad sexual y de género de los/as jóvenes en la dinámica de las instituciones orientadas a la juventud. En Revista argentina de estudios de juventud, 1 (1). Facultad de Periodismo y Comunicación Social Universidad Nacional de La Plata. S/p.

Epstein, D. y Johnson, R. (2000). Sexualidades e institución escolar. España: Ediciones Morata.

Femenías, M. L.; Aponte Sánchez, E. (2008). Articulaciones sobre violencia contra las mujeres. La Plata: Edulp.

Femenías, M. L.; Soza Rossi, P. V. (2009). Poder y violencia sobre el cuerpo de las mujeres. En: Revistas Sociologías, 21, Universidad Federal de Rio Grande do Sul. pp. 42-65.

Femenías, M. L. (2013). Violencias cotidianas (en la vida de las mujeres). Los Ríos subterráneos. Vol. 1. Rosario: Prohistoria.

Femenías, M. L. (comp.) (2015). Violencias cruzadas. Miradas y perspectivas. Rosario: Prohistoria.

Fidel. C. (coord.) (2014). Mujeres: violencias y sociedad urbana. Bernal: Universidad Nacional de Quilmes. Buenos Aires: Centro Cultural de la Cooperación.

Greco, B. (2009) Acerca de una confianza instituyente y la palabra sobre sexualidad en la escuela. Reflexiones sobre la experiencia de educar. En Villa, A. (comp.) Sexualidad, relaciones de género y de generación. Perspectivas históricoculturales en educación. Buenos Aires: Noveduc.

Lagarde, M. (2008). Antropología, feminismo y política: violencia feminicida y derechos humanos de las mujeres. En: Bullen, M. y Diez, C. (coords). Retos teóricos y nuevas prácticas. España: Ankulegi Antropología.

Laurenzo, P; Maqueda, M.L.; Rubino, A. (coords.) (2009). Género, violencia y derecho. Buenos Aires: Editores del Puerto.

Lavigne, L. (2011). Las sexualidades juveniles en la educación sexual integral. En Elizalde, S., (coord.), Jóvenes en cuestión. Configuraciones de género y sexualidad en la cultura. Buenos Aires: Biblos.

Marshall, D. (2010). Acoso homofóbico, derechos humanos y educación: Una perspectiva no deficitaria de las políticas y prácticas de bienestar para la juventud queer. Revista Archivos de Ciencias de la Educación, 4 (4), 1-16. Recuperado de: http://www.archivosdeciencias.fahce.unlp.edu.ar.

Massolo, A. (2007). Análisis y propuestas para la acción de los gobiernos en la seguridad de las mujeres en las ciudades. En Palú, A.; Segovia, O. (eds.) Ciudades para convivir: sin violencia hacia las mujeres. Santiago de Chile: Ediciones Sur.

Mello, L., Bruno de Alvear, R. y Brito, W. (2014). Políticas públicas de segurança para a população LGBT no Brasil. Revista Estudos Feministas, 22(1), 297-320. Recuperado de: https://dx.doi.org/10.1590/S0104-026X2014000 100016.

Morgade, G. (12 de septiembre de 2016). La educación sexual integral hace a la escuela más justa pero también más interesante. En: Página/12. Recuperado de: https://www.pagina12.com.ar/diario/dialogos/21-309170-2016-0 9-12.html

Pinos-Vélez, V. y Pinos, G. (2011). Actitudes de los adolescentes escolarizados de Cuenca hacia la diversidad sexual. En Revista MASKANA, 2 (1) 1-16.

Platero Méndez, R. (2008). La homofobia como elemento clave del acoso escolar homofóbico. Algunas voces desde Rivas Vaciamadrid. Revista Información Psicológica, 98, 71-83.

Segato, R. (2003). Las estructuras elementales de la violencia. Ensayos sobre género entre la antropología, el psicoanálisis $y$ los derechos humanos. Bernal: Universidad Nacional de Quilmes.

Segato, R. (2017). La guerra contra las mujeres. Buenos Aires: Tinta Limón.

Torres, G. (2008). Normalizar: discurso, legislación y educación sexual. En Revista ICONOS, 35, 31-42. Facultad Latinoamericana de Ciencias Sociales-Sede Académica Ecuador.

Stonewall (2018). Sitio oficial: https://www.stonewall.org.uk/

Venturi, G. y Bokany, V. (2011).Diversidade Sexuale Homofobia no Brasil. Intolerância e Respeito às Diferenças Sexuais. São Paulo: Editora Fundação Perseu Abramo. 
Zemaitis, S. (2016) Pedagogias de la sexualidad. Antecedentes, conceptos e historia en el campo de la educación sexual de la juventud. Trabajo Final de Especialización en Nuevas Infancias y Juventudes, Facultad de Humanidades y Ciencias de la Educación, Universidad Nacional de La Plata, La Plata.

\section{DOCUMENTOS, NORMATIVAS E INFORMES CITADOS}

Argentina (2006). Ley 26.150 de Educación Sexual Integral.

Argentina. Ministerio de Educación de la Nación (2008). Lineamientos Curricularespara la Educación Sexual Integral. Buenos Aires.

Argentina. Ministerio de Educación de la Nación (2015). Educación Sexual Integral en la Argentina. Voces desde la escuela. Buenos Aires.

Argentina (2016). Primera Encuesta Nacional de clima escolar para jóvenes LGTB. Asociación Civil 100\% Diversidad y Derechos.

Brasil. Secretaria de Direitos Humanos (2011[2012]). Relatório sobre violência homofóbica no Brasil. Recuperado de: $\mathrm{h}$ ttp://www.sdh.gov.br/assuntos/lgbt/pdf/relatorio-violencia-homofobica-2011-1. Última consulta: 16 de mayo de 2018.

Colombia. (2016). Encuesta de Clima Escolar LGBT. Senttido y Colombia Diversa. Recuperado de: http://colombia diversa.org/colombiadiversa2016/wp-content/uploads/2016/11/IAE-Colombia-Web-FINAL-2.pdf

Comisión Interamericana de Derechos Humanos (2014). Una mirada a la violencia contra personas LGBT. Comunicado $n^{\circ} 153 / 14$.

Comisión Interamericana de Derechos Humanos (2015). Violencia contra personas LGBTI. OEA. Chile.

Chile. MOVILH (2012). Encuesta sobre educación sexual y discriminación. Santiago, Chile: MOVILH. Recuperado de: http://www.movilh.cl/

Homozapping. La mitad de estudiantes LGBT son victimas de bullying homofóbico en la escuela. Recuperado de: http://homozapping.com.mx/2017/05/la-mitad-de-estudiantes-lgbt-son-victimas-de-bullying-homofobic o-en-la-escuela/ (Última consulta: 27/5/2018).

México (2012). Primera encuesta Nacional de bullying homofóbico. Youth Coalition \& COJESS. Recuperado de: htt $\mathrm{p}: / /$ www.enehache.com

Perú. (2013-2014) Informe anual sobre derechos humanos de personas trans, lesbianas, gays y bisexuales en el Perú. Recuperado de: https://issuu.com/promsex/docs/informetlgb2013-2014

UNESCO. Oficina Regional de Educación para América Latina y el Caribe. OREAL/UNESCO: Santiago de Chile (2013). Respuestas del sector de Educación frente al bullying homofóbico.

Venezuela. (2013). Informe Venezuela 2013, Resultados Preliminares "Crímenes de odio por Orientación sexual, Identidad de género y Expresión de género en la noticia de los Medios de Comunicación y Organizaciones de la Sociedad Civil”, Revisión Hemerográfica Enero 2009 a agosto 2013 publicado por ACCSI Acción Ciudadana Contra el SIDA.

\section{Notas}

1 Lxs autorxs agradecen la lectura crítica y los comentarios realizados por el Lic. Gabriel Quinzani (UNLP).

2 La sigla LGBTI referencia a las identidades lesbianas, gays, bisexuales, transexuales, transgéneros, travestis e intersexuales. Desde ya, lxs autorxs de este artículo reconocen que cada una de estas identidades, grupos o colectivos de identificación tienen a su vez problemáticas distintas a los otros. Podríamos pensar que, aun así, tales identificaciones se alejan de las identidades clásicas de las normas del género (varón=masculino; mujer=femenina) y/o de la orientación sexual (heterosexualidad). En el artículo se han respetado los diferentes órdenes de nombramiento de cada identidad cuando se referencian estudios y encuestas. En algunos casos se indican como LGBT, en otros como GLBT. 
3 Por ejemplo, el póster "Hoy puede ser un buen día... para trabajar Educación Sexual Integral” producido por el Programa de ESI; o el que propone recordar, bajo la consigna "Respetar la diversidad", que el 17 de mayo es el Día Internacional contra la Discriminación por Orientación Sexual y la Identidad de Género.

4 No podemos dejar de mencionar que actualmente este Programa ha visto reducido su desarrollo por el recorte presupuestario realizado durante la gestión del gobierno de Cambiemos en el marco del cual dejaron de realizar capacitaciones masivas y no volvieron a imprimirse los cuadernillos y las láminas del programa. Sin embargo, contamos con indagaciones específicas en torno a los avances normativos y curriculares en materia de educación sexual -tanto a nivel nacional como la ley de educación sexual sancionada en la Ciudad Autónoma de Buenos Aires (CABA)-, que, impulsadas luego de la sanción de la Ley ESI, han explorado dichos avances y prácticas, y también analizado las perspectivas ideológicas y conceptuales que dichos marcos sostienen (Torres, 2008; Boccardi, 2008, 2010; Lavigne, 2011).

5 También forman parte de la OEA: Barbados, Belice, Bolivia, Brasil, Canadá, Chile, Colombia, Cuba, Ecuador, El Salvador, Estados Unidos, Guatemala, Guyana, Haití, Honduras, Jamaica, México, Nicaragua, Panamá, Paraguay, Perú, República Dominicana, Uruguay y Venezuela.

6 Elaborada por las organizaciones sin fines de lucro Sentido y Colombia Diversa. Esta encuesta, pionera en Colombia, arrojó que de 581 estudiantes LGBT encuestados, entre los 13 y 20 años de edad, el $67.0 \%$ informó que se sintió inseguro/a en su colegio debido a su orientación sexual, y más de la mitad, un $54.8 \%$, se sintió inseguro/a debido a la manera como expresa su género. Asimismo, otro dato a destacar es que el $68.9 \%$ asumió haber escuchado a otros estudiantes haciendo comentarios homofóbicos (ejemplifican los descalificativos como "maricón”, “arepera” o "loca”).

7 Desde el año 2011, el estado brasilero ha venido aplicando diferentes encuestas para conocer el estado de situación sobre las violencias contra las personas LGBT. Coordinadas e impulsadas desde la Secretaría de Derechos Humanos de la Presidencia de la República, en 2011 y 2012 se presentaron los resultados del Informe sobre violencia homofóbica en Brasil, basados en las denuncias realizadas por personas hostigadas. Ambos estudios se realizaron sobre la base de un registro de " 1.159 denuncias, relativas a 6.809 violaciones de derechos humanos contra LGBT denunciadas al Gobierno Federal en 2011, involucrando a 1.713 víctimas y 2.275 sospechosos. En 2012, el número de denuncias llegó a 3.084, con 9.982 las violaciones, 4.851 víctimas y 4.784 sospechosos, lo que corresponde a aumentos respectivos del 166,9\%, el 46,6\%, el 183,19\% y el 110,19\%, comparando los datos de 2011 y 2012” (Mello, Bruno de Alvear y Brito, 2014, p. 301) (la traducción es nuestra). En relación a los lugares donde se ha ejercido algún tipo de violencia, en el Informe del 2011 se especifica que, tanto en las investigaciones nacionales como en las internacionales, las violencias acontecen en espacios públicos (calles, plazas, escuelas, hospitales, restaurantes). Puede consultarse también la investigación de Gustavo Venturi y Vilma Bokany (2011), bajo la organización de la Fundação Perseu Abramo y la Fundação Rosa Luxemburgo Stiftung que recogemás de 2.000 testimonios en 150 municipios brasileros.

8 Se trata de documentos organizados por la Red Peruana TLGB y el Centro PROMSEX. A diferencia de la mayoría de los informes y estadísticas de la región, en este caso no refieren a encuestas realizadas a la población LGBT., sino que sistematizan los avances, deudas y demandas que el Estado peruano y las organizaciones vienen realizando en materia de protección de derechos de las personas LGBT. Entre otros, derecho a la educación, a la participación política y a tener una familia.

9 Este último sondeo, realizado bajo una encuesta a 237 personas LGBT, advirtió que 219 de ellas (92\%) "respondieron haber sido víctimas de discriminación y violencia por la condición de LGBTI en varias regiones del país; 199 (82\%) dicen que alguna vez fueron agredidas verbalmente por ser LGBT; 117 (73\%) expresaron haber pensado emigrar por la discriminación aunque seguían viviendo en Venezuela; 47 de las personas encuestadas dijeron que no denunciaron las agresiones sufridas por desconfianza en el sistema de justicia, vergüenza, falta de información sobre posibilidades de denuncia, miedo a represalias, entre otros. En cuanto a la discriminación en el ámbito escolar o universitario durante los últimos 5 años, 111 (46,84\%) personas dijeron creer que la discriminación continuaba igual, en cambio 131 (55,27\%) afirmaron que la aceptación de la comunidad había aumentado". (Informe Venezuela 2013, p. 8).

10 La encuesta fue promovida en América Latina por la UNESCO y apoyada en nuestro país por CTERA. Para acceder al informe completo ingresar a: https://100porciento.files.wordpress.com/2016/12/informe-final-encuesta-de-climaescolar-lgbt.pdf (consultada el 2/12/2018).

11 Aclaramos que aunque el informe menciona en su título al colectivo "LGBTI", en el documento utiliza algunas veces esa denominación, y en otras cambia a "LGBT". Decidimos citarlas tal cual figuran en dicho documento, lo mismo con el resto de informes referenciados. 